\title{
Evaluation of activity of internal audit: theoretical features and practical priorities
}

\author{
(Presented by Doctor of Economics, Professor Lehenchuk S.F.)
}

\begin{abstract}
Internal audit is a crucial constituent in supporting the management of the prosperous entity in the circumstances of the competitive economy. The significant structural variations that have taken place in recent years both in the Republic of Moldova and in the world, the determination of new priorities in economic development, the formation of a new management system within the economic entity have contributed to the development of internal audit in several countries. A keen interest in the implementation of internal audit also belongs to the owners, who are interested in monitoring the effectiveness of material, financial and human resources within the entity. The internal audit is actively implemented in the entity's activity, such as in the preparation of economic and financial information, its analysis and evaluation, control over the quality and efficiency of the entity's subdivisions, also on the safety of assets and efficiency of their use, etc. On these grounds, the role of quality assurance of the internal audit activity is currently on the rise, which is in line with its performance. In this context, the author approaches the study of the basic aspects of the internal audit evaluation process in terms of identifying the evaluation method, establishing and interpreting the indicators used in the evaluation, as well as determining the evaluation principles. As a method of evaluation of the quality of the internal audit activity, the author uses the dashboard, determines the basic steps in its use and suggests a list of indicators, which can be applied in the evaluation process. At the same time, the basic functions of using the dashboard in the process of evaluating the work of internal audit are identified.
\end{abstract}

Keywords: internal audit; evaluation indicators; evaluation method.

Topicality. The relevance of the research is subject to the increased interest concerning the evaluation of the internal audit activity, both from the persons entrusted with governance, management of the entity, and from the audited subdivisions. At present, the internal audit activity must validate its contribution to the achievement of the strategic objectives of the modern entity, which operates in the conditions of the competitive economy. Concomitant, internal audit interested parties want audit engagements to provide the entity with added value, the latter being a fundamentally new feature of internal audit work. In this context, it is necessary to determine the method and indicators of evaluation, which would express the quality and performance of the internal audit. Furthermore, clear evaluation criteria must be established, which ensure that adequate results are obtained in the evaluation of the internal audit activity. All these characteristics contributed to the establishment of the research topic and determined the origination of the appropriate purpose of the study.

Analysis of current research and publications, which the author rests upon. The present research is conducted starting from the study of the latest publications in the specialized literature regarding evaluation of the internal audit activity. Here we can remark the Romanian authors C.I. Zinca (Voiculescu) [1], that approach in a professional manner the particularities of measuring the value of internal audit in banking field, A. Vintilescu Belciug, L.C. Brojba, C.Gegea, D.Cretu [2], whose researches are dedicated to quantifying the performance of internal audit in institutions public; Russian researchers E.Zverev [3], O.Ivanov, E.Egorova [4], E.Batasheva [5], whose works reflect practical aspects of evaluation of quality of internal audit. The works of domestic authors V.Paladi, L.Erhan, A.Brașoveanu [6] investigate aspects of estimating performance based on added economic value, and some ideas can be used in evaluation of the added value provided by internal audit. The nominated studies represent a significant contribution in the development of the internal audit evaluation methodology, but there are also debatable characteristics, one of which is the identification of an appropriate evaluation method, which would meet the expectations of interested parties in the internal audit activity.

The aim of this study is to elucidate the basic theoretical and practical characteristics of the evaluation process of the internal audit activity, which include: determining the evaluation method and criteria; establishing the set of indicators used in the evaluation and their proper interpretation, so that they can be used to determine the results of the evaluation. The legislative and normative acts of the Republic of Moldova, also the International Professional Practices Framework in Internal Audit (IPPF) serve as the informational basis of this study.

Presentation of the main research material. International Standards for Professional Practice of Internal Audit (ISPPIA) [7] presents the latest developments in the concept of internal audit, which embodies its notion, namely, internal audit provides independent and objective guarantee and counseling services, designed to convey value to the organization, and increase its operations. At the same time, the internal audit supports an 
organization to achieve its goals through a regular and methodical methodology that evaluates and increases the effectiveness of governance, risk management and control processes.

In this regard, in order to fulfill its role and purposes, provided by practical standards, but also the growing requirements of modern business, internal audit must guarantee a high level of quality of the activities performed, as is evident from previous research conducted by the author [8]. The author notes that, at the international level, special attention is paid to questions related to quality assurance and improvement of quality of internal audit work.

ISPPIA provides certain related requirements for evaluating the quality of internal audit, which are reflected in particular by the following standards:

- 1300 - Quality Assurance and Improvement Program;

- 1310 - Internal evaluations;

- 1312 - External evaluations;

- 1320 - Reporting on the Quality Assurance and Improvement Program.

Thereby, at the level of internal audit subdivisions, a quality assurance and improvement program should be developed, covering all aspects of the practical activity of internal audit. Directly, the role of this program is to evaluate the compliance of audit work with international standards, as well as to evaluate the application of the Code of Ethics by professional auditors. Moreover, the program evaluates the efficiency and effectiveness of the internal audit and must identify aspects for its improvement. In this context, the author developed a model of the analyzed program, which is presented in table 1.

Program of assurance and improvement of the quality of internal audit work

\begin{tabular}{|c|l|}
\hline $\begin{array}{c}\text { No. } \\
\text { of/ord. }\end{array}$ & \multicolumn{1}{|c|}{ Content } \\
\hline A & Program drawing up \\
I & Introduction \\
1.1. & Program aim \\
1.2. & Responsibilities \\
II & Accomplishment \\
2.1. & Internal evaluation \\
2.1 .1$. & Evaluation of the potential of internal audit subdivisions \\
2.1 .2$. & Evaluation of the operational activity of the internal audit subdivisions \\
2.1 .3$. & Establishing the interests and needs of the audit committee \\
2.1 .4$. & Establishing the interests and needs of the entity's management \\
2.1 .5$. & Evaluation of the internal audit mission \\
2.2. & External evaluation \\
2.2 .1$. & Evaluation performed by internal auditors at hierarchically higher levels \\
2.2 .2$. & Evaluation performed by independent external auditors \\
III & Supervisioning the implementation of the program of assurance and improvement of the \\
& quality of internal audit work \\
IV & Approval of the program of assurance and improvement of the quality of internal audit work \\
B & Establishing the action plan on assurance and improvement of the quality of internal audit work \\
C & Report on monitoring the quality of the internal audit activity \\
\hline
\end{tabular}

As follows from the information presented in table 1, the model of the Program of assurance and improvement of the quality of internal audit work is in strict accordance with the requirements set out in its international standards. The basic place in the program belongs to both internal and external evaluations.

It should be mentioned that in the Republic of Moldova, currently the internal audit is mandatory in public entities, and in the private sector - in public interest entities, including banking institutions. In this context, analyzing the legislative and normative framework in force regarding the evaluation of the internal audit activity, the author observes that, at this point, in the Republic of Moldova this includes:

1) in the public sector - Regulation on quality evaluation of the internal audit activity in the public sector, approved by the Decision of the Government of the Republic of Moldova No. 617 of 11.12 .2019 [9];

2) in the corporate sector - Regulation on Banking Activity Management Framework, approved by the Decision of the Executive Committee of the National Bank No. 322 of 20.12.2018 [10].

The Regulation on the evaluation of the quality of internal audit activity in the public sector establishes the necessary requirements for its evaluation, performed by internal and external evaluation within central and local public administration authorities, public institutions, along with autonomous authorities / institutions managing national public budget. 
In the public sector, internal evaluations include: continuous monitoring of the internal audit activity and regular self-evaluations. We acknowledge that continuous monitoring of the internal audit activity is an integral part of the daily activity of supervision, verification and measurement and refers to compliance with the following series of National Internal Audit Standards (NIAS):

- NIAS 2200 - Mission planning;

- NIAS 2300 - Performing the internal audit mission;

- NIAS 2400 - Communicating results;

- NIAS 2500 - Monitoring the actions following the communication of results.

The continuous monitoring activities are completed by the head of the internal audit subdivision, which includes: supervision activity; evaluation of the internal audit mission (including the audited unit); evaluation of the key performance indicators of the internal audit activity. We inform you that the evaluation of the internal audit mission is carried out on the basis of the corresponding evaluation form, and by applying this form as it is observed in particular if: internal auditors collected and processed all the information necessary to establish the objectives of the internal audit engagement and whether they were determined as a result of the risk evaluation; the work program of the internal audit mission ensures the achievement of the objectives of the audit mission with the framing in the allocated time resources and their efficient use; there was effective communication between the internal auditors and the audited unit; during the internal audit mission, the auditors complied with the normative framework, NIAS, card of internal audit, the procedures for carrying out the internal audit activity, along with Code of Ethics of the internal auditor; observations and recommendations made were discussed with the audited unit during the internal audit mission; observations mentioned in the internal audit report belong to the auditable field and have been presented in a relevant and reliable manner; the audit recommendations formulated are in line with the observations presented in the internal audit report, etc.

Simultaneously, the audit unit's evaluation of the internal audit engagement is carried out in order to analyze its satisfaction with the services of the internal auditors, including identifying opportunities for continuous improvement of the auditors' work. Immediately, the results of the evaluation of the internal audit mission are completed through its evaluation questionnaire.

Along with that, the head of the internal audit subdivision ensures the establishment, measurement, continuous analysis and at least annual reporting of the key performance indicators of the internal audit activity. Analysis of the list of given indicators allowed us to find that this does not include the assessment of satisfaction degree of the head of the public entity related to the internal audit activity. We think that the inclusion of this indicator would allow a broader and more appropriate conclusion to be drawn on the work of internal auditors.

Another important matter of internal evaluations, as mentioned above, is the self-evaluation of the quality of the internal audit activity, which can be performed by the head of the internal audit subdivision or a team of internal auditors, who have the appropriate professional training. Self-evaluation process includes the complex examination of the internal audit activity, which focuses on the mechanism for performing the internal audit missions carried out during the reference period and the results obtained are reflected in an appropriate form, stipulated in the analyzed Regulation.

We state that self-evaluation of the quality of the internal audit activity directly addresses the compliance with the criteria deriving from the Code of Ethics of the internal auditor and from the following series of NIAS: 1000 - Mission, competencies and responsibilities; 1100 - Independence and objectivity; 1200 - Professional competence and conscientiousness; 1300 - Program of assurance and improvement of the quality of internal audit work; 2000 - Management of the internal audit activity; 2100 - Nature of work; 2200 - Mission planning; 2300 - Performing the internal audit mission; 2400 - Communicating results; and 2600 - Communication of acceptance of risks. Each evaluation criterion is assigned a score, using a scale from 0 to 3 , as follows: 3 - is fully completed; 2 - requires some improvements; 1 - requires significant improvements; 0 - is unrealized and n.a. - not applicable, which is used in exceptional cases and always requires a justification.

The following criteria are used in order to evaluate internal audit activity:

- fully compliant (FC), 95-100\% - internal audit activity fully meets the requirements provided in the regulatory framework and there are opportunities to improve it on some insignificant aspects;

- general compliance (GC), 75-94\% - internal audit activity meets the requirements provided in the regulatory framework, but not entirely and requires perfections of its quality assurance system, along with the mechanism for performing internal audit missions;

- partially compliant (PC), 50-74\% - the accomplishment of the internal audit activity deviates from the regulatory framework, partially fulfilling the stipulated requirements, thus it requires significant improvements of the quality assurance system of the given activity and of the mechanism for accomplishing the missions of Internal Audit;

- non-compliant (NC), 0-49\% - the internal audit activity does not meet most of the requirements provided in the regulatory framework, and its quality assurance system and the mechanism for performing internal audit missions have major deficiencies, having a significant impact on the effectiveness of the audit and the potential to add value to the entity. 
At the same moment we notify that the external evaluation of the quality of the internal audit activity is performed based on the same evaluation criteria, mentioned above, and its results are communicated to the manager of the public entity, the head of the internal audit subdivision, as well as the Ministry of Finance and other interested parties.

Direct references to the evaluation of the internal audit in the private sector can be found in the second regulation nominated in this work - Regulation on Banking Activity Management Framework, specifically in the part that regulates the activity of the Bank's Audit Committee. Thereby, the Audit Committee's responsibilities include monitoring the effectiveness of the internal control and risk management systems and, where appropriate, the internal audit function, without prejudice to its independence with regard to the bank's financial reporting. After the analysis of this regulation, we find that it does not contain information related to the evaluation method and, accordingly, does not present indicators, which can be used in the evaluation.

In these circumstances, an issue of the evaluation of the internal audit activity in the corporate sector represents the following aspects:

- establishing the evaluation method;

- identification of evaluation criteria;

- establishing the list of indicators used in the evaluation.

The problem is amplified by the fact that, currently, the regulatory framework for internal audit in the private sector in the country does not contain provisions on the mandatory application of IPPF, nor on compliance with it. In our view, the solution would be the voluntary application of IPPF provisions, the more that the Institute of Internal Auditors (IIA) has developed a Practical Guide on evaluating the effectiveness and efficiency of internal audit. We agree with the opinion of the Russian researcher E.Zverev [3], who states that the questions related to the evaluation of the internal audit activity are current and debatable, despite the fact that the internal audit is related to the strategy of the entity and interacts directly with its senior management.

As previously mentioned, according to the trends in internal audit, it should add value to the entity. In order to create value, in the opinion of local researchers V.Paladi, L.Erhan, A.Braşoveanu [6], it is necessary to make investments. Therefore, internal audit requires investment, and its results cannot always be expressed by quantitative indicators. In this respect, we can mention the significant contribution in the theory and practice of internal audit brought by the Romanian authors C.I. Zinca (Voiculescu) [1], which studies the particularities of measuring the value of internal audit in banking, A. Vintilescu Belciug, L.C. Brojba, C.Gegea, D.Cretu [2], whose research is dedicated to quantifying the performance of internal audit in public institutions; by Russian researchers E.Zverev [3], O.Ivanov, E.Egorova [4], E.Batashev [5], investigated the practical aspects of evaluating the quality of internal audit.

Furthermore, the author presents the aspects, which he considers to be important in the process of evaluating the internal audit activity in the corporate sector in the Republic of Moldova. It is basic to establish consolidated evaluation criteria, i.e. the internal audit activity must correspond to the IPPF and the strategic objectives of the entity, which are intended at improving its activity. We notify that the strategic objectives represent the key results, the achievement of which the entity proposes. Concomitant, the indicators for assessing the effectiveness of the internal audit activity, which fall within this criterion, must be in line with these objectives. At the same time, the change in strategic objectives must lead to changes in the indicators used to evaluate the internal audit activity.

We mention that another important aspect in evaluating the quality of internal audit activity is the establishment of appropriate evaluation indicators. Considering the fact that internal audit is a key element in the entity's corporate governance, the evaluation of its business should include relevant indicators, which are determined by identifying the interests and needs of interested parties. The main interested parties in quality internal audit services are the audit committee and the entity's management.

In determining the evaluation indicators, it is possible to use the corresponding Guide, elaborated by the IIA, which includes a card for establishing the corresponding indicators, the recommendations of which are of a general nature. At the same time, we believe that the internal audit subdivisions must draw up their own card, taking into account the specifics of the entity and the level of development of the audit structure. The nominated card must include indicators that are accessible and understandable to all persons involved in the evaluation and analysis of the evaluation results.

In our opinion, the list of evaluation indicators should be established by the head of the internal audit subdivision. For its composition we consider that it is to undertake the following:

- $\quad$ to get in line the internal audit subdivision strategy with the list of indicators, following compliance with IIA standards, with other professional regulations, which must ensure that the needs of interested parties are met;

- $\quad$ to ensure the use of both quantitative and qualitative indicators;

- $\quad$ to ensure the permanent monitoring of the indicators and their reporting.

We acknowledge that a basic concern of the head of the internal audit subdivision is to establish a balanced set of indicators for evaluating the internal audit activity. The balance of indicators is directly ensured by the appropriate use of the interests and needs of interested parties, also the potential and operational activity of the internal audit subdivision. 
In our opinion, both quantitative and qualitative indicators are significant for demonstrating the quality of internal audit to interested parties. Directly quantitative indicators are based on existing or available data and, correspondingly, require less effort to collect, being comparable to the same indicators from other entities with similar activities. At one time, qualitative indicators are based on the collection of unique information, through more complex methods, among which we could mention the interview or data analysis. These indicators provide a broader picture of internal audit and can ensure a better understanding of quantitative indicators. However, it is essential that the head of the internal audit subdivision ensures an optimal balance of quantitative and qualitative indicators, which is linked to the identification of basic interested parties, whose needs are given priority.

Thereafter it is necessary to establish the evaluation method by the head of the internal audit subdivision. For that, the methods for evaluating the performance of activities, including the internal audit activity, which are used in the practice of the entities, are to be researched. We note that one of the most appreciated evaluation methods is based on the use of the dashboard [1], which highlights the link between the internal audit objectives and the entity's objectives. At the same time, the study undertaken allows us to make a synthesis of the main functions of the use of the dashboard in the process of evaluating the quality of internal audit:

- function of informing the head of the internal audit subdivision about the situation of the internal audit at the entity;

- $\quad$ warning function on unfavorable situations to be improved;

- function of evaluating the results obtained;

- decision making function, which provides the decision making aspect of the persons responsible for internal audit activities.

In this respect, in the present research the author of the thesis used the dashboard to develop a set of indicators, which provides an overview of the evaluation of the quality of internal audit. The main steps in using the dashboard are:

- determining noteworthy aspects and developing dashboard indicators;

- $\quad$ quantify the value of the indicators used in the evaluation;

- $\quad$ aggregating the quantification of the value of the indicators.

At the stage - Defining the significant aspects and developing the dashboard indicators, the following important aspects for the internal audit are identified:

- financial perspective;

- perspective - the interests and requests of the audit committee and the management of the entity;

- perspective - the operational activity of the internal audit subdivisions;

- perspective - the potential of internal audit subdivisions.

Furthermore, the author defines the strategic objectives for each aspect and, corresponding to each objective the evaluation indicators, which are presented in table 2 . We note that the developed indicators were directly implemented in the practice of the internal audit subdivision of S.A. «ALPHA LEASING».

Table 2

Elaboration of indicators from the dashboard for internal audit

\begin{tabular}{|c|c|}
\hline Strategic targets & Evaluation indicators \\
\hline \multicolumn{2}{|r|}{ Perspective - Financial } \\
\hline $\begin{array}{l}\text { - Framing in the internal audit budget. } \\
\text { - Performing missions of internal audit } \\
\text { with value added }\end{array}$ & $\begin{array}{l}\text { - Percentage of audit missions completed within budget. } \\
\text { - Savings following the implementation of the recommendations }\end{array}$ \\
\hline \multicolumn{2}{|r|}{ Perspective - Client } \\
\hline $\begin{array}{l}\text { - Degree of satisfaction of the audit } \\
\text { committee and the management of the } \\
\text { entity }\end{array}$ & $\begin{array}{l}\text { - Evaluating the degree of satisfaction. } \\
\text { - Assurance on the adequacy of the internal control system. } \\
\text { - Assurance on the adequacy of risk management. } \\
\text { - Quota of accepted recommendations. } \\
\text { - Quota of recommendations achieved. } \\
\text { - Changes made in the entity's processes }\end{array}$ \\
\hline \multicolumn{2}{|c|}{ Perspective - Operational activity of the internal audit structure } \\
\hline $\begin{array}{l}\text { - Risks coverage. } \\
\text { - Conformance with ISPPIA }\end{array}$ & $\begin{array}{l}\text { - Level of reduction / elimination of identified risks. } \\
\text { - Fulfillment of the internal audit plan. } \\
\text { - Number of recommendations for an audit. } \\
\text { - Evaluation of compliance with ISPPIA }\end{array}$ \\
\hline \multicolumn{2}{|c|}{ Perspective - The potential of the internal audit structure } \\
\hline $\begin{array}{l}\text { - Development of staff skills. } \\
\text { - Sustaining innovations }\end{array}$ & $\begin{array}{l}\text { - Number of hours conducted in professional development. } \\
\text { - Quota of employees holding professional certificates. } \\
\text { - Number of new audit methods used. } \\
\text { - Number of newly identified risks }\end{array}$ \\
\hline
\end{tabular}


In the further step «Quantification of the value of the indicators used in the evaluation» for each indicator used in the evaluation, projected values and the actual values are established. In these circumstances, we find that another important aspect in the application of the dashboard for the evaluation of the internal audit activity is the development of evaluation tools. Therefore, for each of the identified evaluation indicators, appropriate evaluation tool is determined. Thereafter, the author presents the evaluation tool - interested parties Questionnaire, for the perspective - Client, strategic objective - satisfaction degree, which was developed and implemented in the entity's practice S.A. «ALPHA LEASING».

Table 3

Questionnaire on satisfaction degree of the Audit Committee related to the internal audit activity

\begin{tabular}{|c|c|c|c|}
\hline Content of the questions & $\begin{array}{l}\text { High, } \\
10 \text { poin. }\end{array}$ & $\begin{array}{l}\text { Partial, } \\
5 \text { poin. }\end{array}$ & $\begin{array}{l}\text { Reduced, } \\
3 \text { poin. }\end{array}$ \\
\hline $\begin{array}{l}\text { 1. Is there an appropriate communication between the head of the audit } \\
\text { structure and the Audit Committee? }\end{array}$ & $\sqrt{ }$ & & \\
\hline 2. Are audit reports prepared in an appropriate time? & & $\sqrt{ }$ & \\
\hline $\begin{array}{l}\text { 3. Does the content of the audit reports allow the Audit Committee to } \\
\text { take effective action? }\end{array}$ & $\sqrt{ }$ & & \\
\hline $\begin{array}{l}\text { 4. Are the internal audit activities coordinated with the Audit } \\
\text { Committee? }\end{array}$ & $\sqrt{ }$ & & \\
\hline $\begin{array}{l}\text { 5. Does the internal audit contribute to strategic and operational } \\
\text { decisions? }\end{array}$ & $\sqrt{ }$ & & \\
\hline $\begin{array}{l}\text { 6. Does internal audit contribute to improving the risk management } \\
\text { process? }\end{array}$ & & $\sqrt{ }$ & \\
\hline 7. Are the significant risks identified and evaluated? & & $\sqrt{ }$ & \\
\hline $\begin{array}{l}\text { 8. What is the response of the management of the entity to the } \\
\text { recommendations of the internal audit? }\end{array}$ & $\sqrt{ }$ & & \\
\hline 9. Does internal audit evaluate the possibility of fraud occurring? & & $\sqrt{ }$ & \\
\hline 10. Does internal audit contribute to improving internal control? & $\sqrt{ }$ & & \\
\hline $\begin{array}{l}\text { 11. Does internal audit contribute to improving the promotion of } \\
\text { ethical conduct in the entity? }\end{array}$ & $\sqrt{ }$ & & \\
\hline 12. Are the planning of internal audit activities carried out properly? & $\sqrt{ }$ & & \\
\hline 13. Are the resources of the internal audit structure used properly? & $\sqrt{ }$ & & \\
\hline $\begin{array}{l}\text { 14. Do internal auditors have skills and competencies specific to the } \\
\text { entity's field of activity? }\end{array}$ & & $\sqrt{ }$ & \\
\hline 15. Is the independence and objectivity of internal auditors ensured? & $\sqrt{ }$ & & \\
\hline $\begin{array}{l}\text { 16. Does the degree of use of technology in the internal audit activity } \\
\text { correspond to its needs? }\end{array}$ & & $\sqrt{ }$ & \\
\hline 17. Is the internal audit plan reviewed to determine the relevant risks? & & $\sqrt{ }$ & \\
\hline 18. Is the internal audit structure adequately dimensioned? & & $\sqrt{ }$ & \\
\hline $\begin{array}{l}\text { 19. Does the internal audit structure have a continuous professional } \\
\text { development program for employees? }\end{array}$ & & $\sqrt{ }$ & \\
\hline 20. Are the results of the internal audit evaluation analyzed? & & $\sqrt{ }$ & \\
\hline
\end{tabular}

Source: drawn up by the author based on the information S.A. «ALPHA LEASING»

Author has established that the questions included in the questionnaire fully reflected the basic interests and needs of the Audit Committee related to internal audit. Directly, the projected value of this indicator can be 10 points, i.e. a maximum assessment by the entity's Audit Committee. For a partial and unsatisfactory assessment, 5 and 0 points can be used accordingly.

For the financial perspective, the strategic objective - Framing in the internal audit budget, the indicator «Percentage of audit missions completed within budget» the auditor sets as the projected value 1 (i.e. $100 \%$ of internal audit missions to be completed within budget). At the end of the year, based on the financial documentation of the audit engagement, the actual value of this indicator can be determined directly. Table 4 presents the interpretation of the indicators used to evaluate the quality of the internal audit activity. 
Interpretation of indicators used to evaluate the quality of internal audit activity

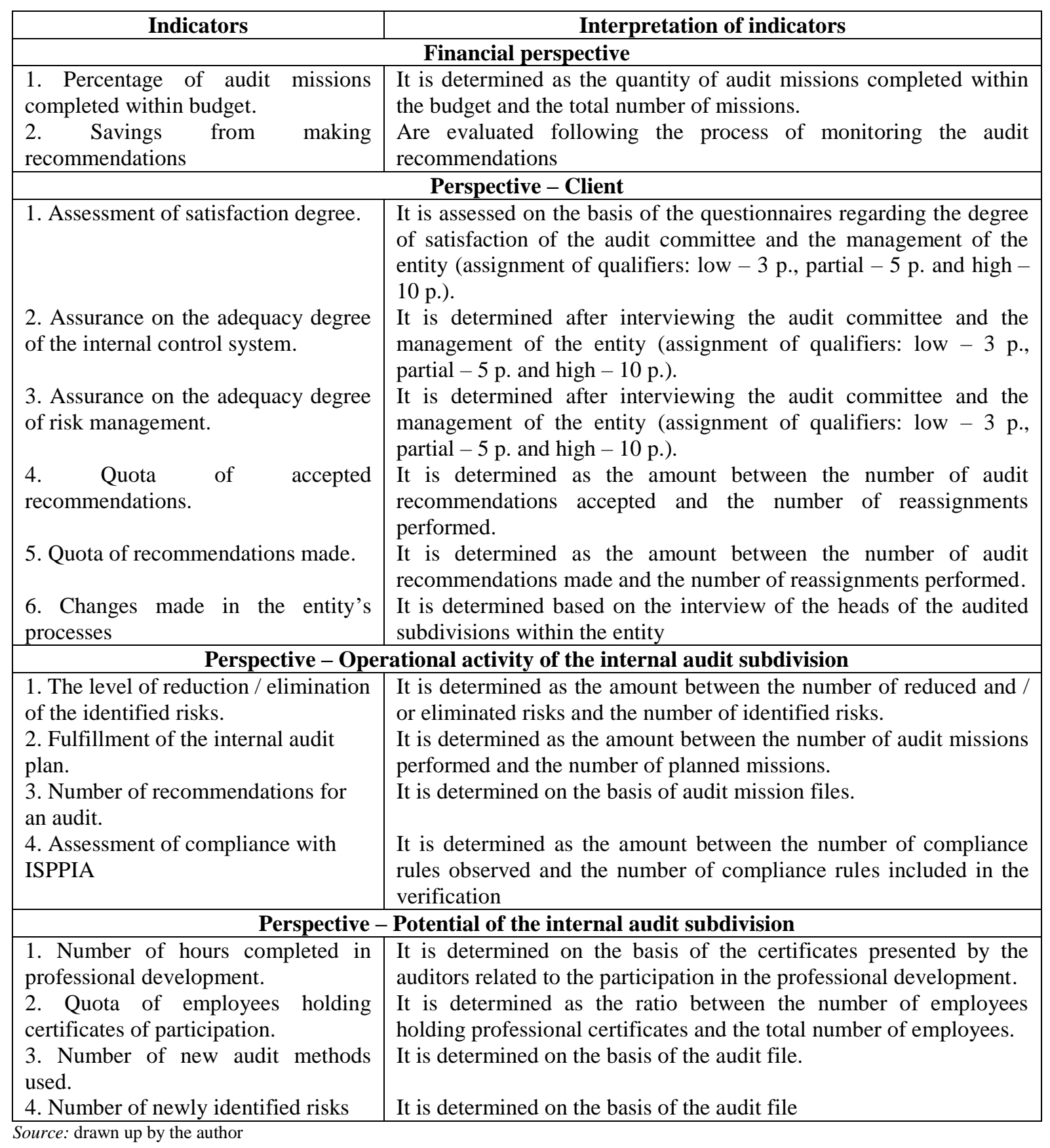

As we can see, the information presented in table 4 permits internal auditors to interpret each of the indicators included in the dashboard, and they can then be used in the next step, established by the author, namely the step - Aggregation of quantification of indicators.

Conclusions and prospects for subsequent research. Achieving the goals of the internal audit in accordance with the requirements stipulated in the IPPF, is to guarantee a high level of quality of the activities performed by it. Moreover, as internal audit becomes an important resource for the entity's current and potential owners and investors and other interested persons, it must demonstrate credibility toward given individuals. In the present research, the author performed a comprehensive analysis of the normative acts related to the evaluation of the internal audit both in the public and in the private sector of the Republic of Moldova. The results of the analysis show us that in the public sector, the methodology for evaluating the internal audit activity is established, which includes internal and external evaluations. Nevertheless, the mentioned evaluations must be performed in accordance with the provisions of certain NSIA, nominated in the author's work. 
Simultaneously, in the corporate sector, the framework for the practical regulation of the internal audit activity, including the aspects related to its evaluation, is not currently established. Author identified the basic aspects of the evaluation process, which comprises: establishing the evaluation method; identifying the evaluation criteria and establishing the list of indicators used in the evaluation. Author also identified the basics of using the dashboard to evaluate internal audit activity, which include:

1. Determining significant aspects and developing dashboard indicators.

2. Quantification of the value of the indicators used in the evaluation.

3. Aggregation of quantification of the value of indicators.

The first two steps in the use of the dashboard were presented and explained directly, and the elucidation of its last stage is the perspective for future research, which will be addressed by the author in the continuation of the study on the evaluation of internal audit activity.

\section{References:}

1. Zinca (Voiculescu), C.I. and Petroianu, G.O. (2017), «The role of internal audit in credit institution risk management», Economics, No. 3 (101), pp. 93-103.

2. Vintilescu, A. et al. (2010), «Quantifying the performance of internal audit in public institutions», Financial Audit, No. 3, pp. 10-17.

3. Zverev, E. (2018), «Evaluation of Internal Audit Activities: Application of the Institute of Internal Auditors' Practical Guidelines», Joint Stock Company, No. 7/170, pp. 42-49.

4. Ivanov, O. and Egorova, E., «The future of internal audit is being created today», [Online], available at: https://cyberleninka.ru/article/n/buduschee-vnutrennego-audita-sozdaetsya-segodnya

5. Batasheva, E. (2020), «Key performance indicators of the internal audit unit: of what kind they can be and how to measure them», Joint Stock Company, No. 4, pp. 130-138.

6. Paladi, V., Erhan, L. and Brasoveanu, A. (2014), «Estimation of the entity's performance based on the added economic value», Annals of ASEM, ed. XII, No. 1, pp. 162-166.

7. International Standards for the Professional Practice of Internal Audit, [Online], available at: https://www.aair.ro/fisiere/standarde_2017_romana/IPPF-Standards-2017-Romanian.pdf

8. Petreanu, E. (2019), «Current aspects of ensuring and improving the quality of internal audit activity», Collection of scientific works of USM, CEP USM, Chisinau, Vol. IV, pp. 96-101.

9. «Regulation on evaluating the quality of internal audit activity in the public sector, approved by Government Decision of the Republic of Moldova No. 617 of 11.12.2019» (2019), Official Gazette of the Republic of Moldova, No. 388-392.

10. «Regulation on the framework for managing the activity of banks, approved by the Decision of the Executive Committee of the National Bank of Moldova No. 322 of 20.12.2018» (2019), Official Gazette of the Republic of Moldova, No. 1-5.

11. «Practical guide II-A for the evaluation of the internal audit activity», [Online], available at: http://global.theiia.org

Petreanu Elena Gheorghe - Postgraduate, University Lecturer, State University of Moldova.

Scientific interests:

- evolution and development of internal audit;

- evaluation of internal control, risk management and corporate governance by internal audit;

- procedures of exercising the financial audit. 